\title{
Hyperthyroidism management during pregnancy and lactation (Review)
}

\author{
MIHAI CRISTIAN DUMITRASCU ${ }^{1,2^{*}}$, ADINA-ELENA NENCIU ${ }^{2 *}$, SANDRU FLORICA $^{3,4}$, \\ CATALIN GEORGE NENCIU ${ }^{1,5}$, AIDA PETCA ${ }^{1,6}$, RĂZVAN-COSMIN PETCA ${ }^{1,7}$ and ADRIAN VASILE COMĂNICI ${ }^{8,9}$

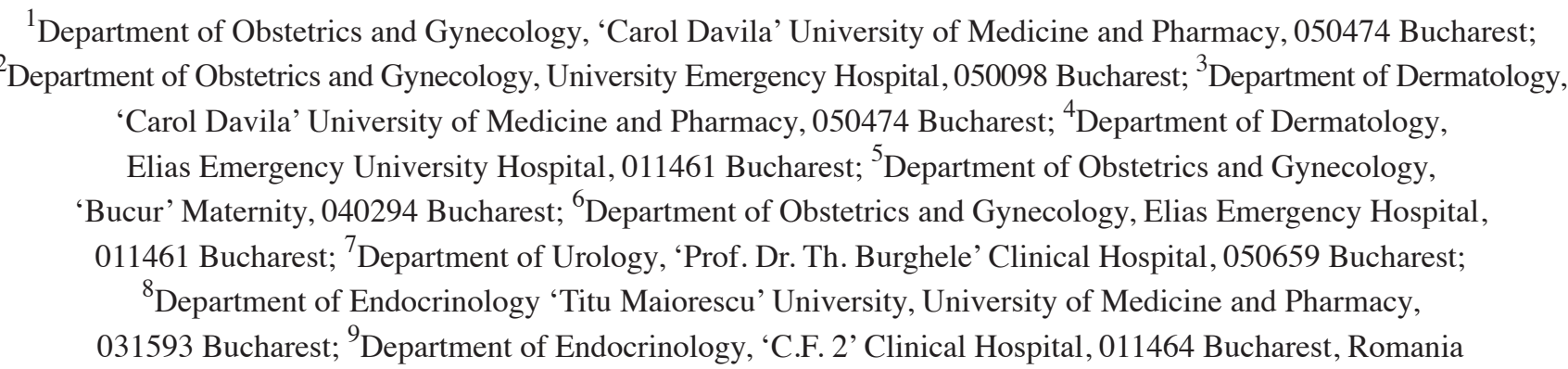

Received April 14, 2021; Accepted May 14, 2021

DOI: $10.3892 /$ etm.2021.10392

\begin{abstract}
Thyroid dysfunction is a significant public health issue, affecting 5-10 more women compared to men. The estimated incidence is up to $12 \%$ and only for women the treatment rises up to 4.3 billion dollars annually. Thyroid pathology can have a major impact on female fertility and it can only be detected when preconception tests are performed. Untreated or poorly treated hyperthyroidism in a mother can affect the fetal development and pregnancy outcome. Between 0.1 and $0.4 \%$ of the pregnancies are affected by clinical hyperthyroidism. Thyroid dysfunction is associated with higher rates of pregnancy loss. Hyperthyroidism can complicate fetal health problems intrauterinely and in the neonatal period. The TSH receptor is stimulated by TSH and HCG which has a similar structure. This can lead to gestational thyrotoxicosis. Hyperthyroidism can be treated with propylthiouracil or methimazole and in selected cases, surgical treatment or radioactive iodine can be chosen. In pregnancy, the most used treatment is represented by propylthiouracil which can be used from the first trimester. The aim of this review is to assess the current data regarding the impact of thyroid dysfunction on pregnancy and to synthesize the treatment options during pregnancy and lactation.
\end{abstract}

Correspondence to: Dr Adina-Elena Nenciu, Department of Obstetrics and Gynecology, University Emergency Hospital, 169 Splaiul Independentei, 050098 Bucharest, Romania

E-mail: dr.nenciu@yahoo.com

*Contributed equally

Key words: pregnancy, breastfeeding, hyperthyroidism, propylthiouracil, methimazole, thyroid dysfunction in pregnancy, gestational thyrotoxicosis

\section{Contents}

1. Introduction

2. Clinical features of pregnant patients with hyperthyroidism

3. Fetal development in pregnancies with hyperthyroidism

4. Treatment options in pregnancy

5. Thyroid dysfunction treatment in lactation period

6. Conclusion

\section{Introduction}

The abridged classification of thyroid diseases includes thyroiditis (with normal thyroid function), hyperthyroidism and hypothyroidism (1). Thyroiditis can be acute, subacute (De Quervain's), chronic autoimmune (Hashimoto's disease) or postpartum and silent thyroiditis (1). In hyperthyroidism the function of the gland can be increased as in Basedow-Graves or not (thyrotoxicosis) as in excessive exogenous thyroid hormones, which can mimic chemical pregnancy in the first weeks of gestation $(2,3)$. Pregnancy is a particular state in a woman's life that occurs due to multiple hormonal and metabolic changes occurring in this period. Although there is controversy, it is considered that thyroid pathology during pregnancy can be associated with fetal and maternal complications including pregnancy loss, preterm delivery, pre-eclampsia and increased neonatal morbidity $(4,5)$. Besides thyroid dysfunction, other endocrine complications such as high blood pressure, adrenal insufficiency, obesity, and diabetes mellitus can severely complicate a pregnancy and modify the outcome of the pregnancy which requires an important level of awareness for obstetricians and necessitates an interdisciplinary team $(6,7)$.

Pregnancy is a period full of hormonal changes. As the estrogen increases, so do the TBG (thyroid binding globulin) and T3 and T4 levels, the serum hCG increases continuously in 
the first trimester and stimulates the TSH receptors responsible in decreasing the TSH levels (8). Thyroid stimulation is due to the similar structure between hCG and TSH which is the cause of decreased serum levels of TSH in pregnant women (9). In addition, iodine availability is relatively reduced due to the increased renal clearance, metabolic changes and fetal intake (10). During this period the thyroid volume increases from 10 to $40 \%$.

A study that included 290 patients with normal pregnancy analyzed the levels of TBG, TBPA, T4, free-T4, T3 and TSH (11). The results showed an increase in TBG levels until 24 weeks, an increase in T4 levels until 16 weeks, a decrease in free-T4 levels to a subnormal value until 20 weeks of pregnancy, an increase in T3 levels until 14 weeks, and an increase in TSH levels until the end of the pregnancy as well as constant TBPA values (11). The normal values specific for each trimester are shown in Table I but are varying (12-14).

The incidence of thyroid pathology among pregnant women varies. It is between 0.1 and $0.4 \%$ for hyperthyroidism and between 2 and $3 \%$ for hypothyroidism (9). In the cases in which thyroid antibodies are present there is a 5-10\% likelihood that the mother will develop thyroid insufficiency in pregnancy (1).

The thyroid function evaluation in pregnancy allows identification of women with a risk of developing thyroid disease or for a woman that already has an alteration of thyroid function. Although there is controversy regarding testing all pregnant patients, the American Thyroid Association (2017) (15), the American College of Obstetrics and Gynecologist (2020) (16) and the European Thyroid Association recommend testing all pregnant patients at high risk for thyroid dysfunction $(17,18)$. Previous findings have shown that thyroid function screening for all pregnant patients does not provide significant differences in the maternal and fetal outcome, but many authors agree on the importance of universal screening in order to identify women with thyroid dysfunction $(5,19)$.

Women considered at risk for developing thyroid pathology are patients $>30$ years, with type 1 diabetes, patients with autoimmune disease, history of infertility, miscarriage or preterm birth, high body mass index, iodine insufficiency or history of irradiation (19). In the same high-risk category are women with thyroid peroxidase antibodies or thyroglobulin antibodies present.

The management of thyroid dysfunction in pregnancy must be balanced carefully. The medical treatment needed (such as anti-thyroid drugs) crosses the placenta and acts on the fetal thyroid. It is important that the cut-off values for thyroid hormones are established and the advantages and disadvantages of the treatment are well presented, with avoidance of under- or over-treatment.

A literature review was performed using PUBMED and COCHRANE databases with the terms 'hyperthyroidism and pregnancy', 'thyroid dysfunction during pregnancy', and 'thyroid dysfunction during lactation'. Current published literature was selected and articles synthetized to the current trend regarding the management of thyroid pathology in pregnancy and the impact of medical treatment on pregnancy and lactation.

\section{Clinical features of pregnant patients with hyperthyroidism}

The symptomatology in hyperthyroidism includes nervousness, dyspnea, tachycardia, cardiac systolic murmur or sweating (6).
These are hard to be correlated with thyroid dysfunction due to their presence in many pregnant women. Patients presenting with weight loss (without significant hyperemesis gravidarum), goiter or ophtalmopathy can be correlated with Graves hyperthyroidism (19). The TSH and FT4 dosage is necessary for diagnosis and it must be correlated with the trimester of the pregnancy (suppressed TSH, elevated FT4). If the patient did not perform thyroid function evaluation in the preconception period, the diagnosis was usually made in the first trimester. Transient hyperthyroidism of hyperemesis gravidarum is defined as transient hyperthyroidism that is limited to the first trimester with the absence of thyroid autoimmunity (20). In these cases, at the beginning of the second trimester the fT4 normalizes but the TSH level may remain low (21).

The physiological changes during pregnancy lead to fluctuating hormonal levels. The main hormone that rises in the first weeks of pregnancy is represented by hCG (human chorionic gonadotropin), which is similar to TSH $(22,23)$. This competition in stimulating the thyroid determines an elevation in free T4 (24,25). In addition, the circulating estrogen increases and leads to an increased thyroxine-binding globulin (TBG) which is also compensated with increased thyroid volume thereby elevating free T4 $(26,27)$. After the first trimester hCG levels decline, the free T4 increases and TSH decreases $(25,28)$. The organism method to protect the fetus is represented by the placental deiodinase type 3 (D3) expression in high amounts, especially in the first trimester (29). D3 deactivates T4 and converts it into a metabolically inactive compound. D3 and deiodinase 2 (D2) are expressed by the brain in various regions of the nervous system and contribute to its protection (28). In addition, the placenta itself is an important barrier which maintains the fetus euthyroid by regulating the thyroid hormone transfer (30). The specific immunosuppression in pregnancy leads to decreasing levels of antibody titers with the progression of pregnancy, but after birth, the antibody titers level increases, including TRAbs. This may lead to postpartum thyroiditis and needs adequate treatment $(27,31)$ even if Graves disease was previously treated (surgery or radioiodine ablation) (28).

These pathophysiological changes lead to the signs and symptoms that are encountered in pregnant women with thyroid dysfunction. Even if they are signs of normal pregnancy, the hormonal dosage should be recommended and detailed history must be obtained.

\section{Fetal development in pregnancies with hyperthyroidism}

Although it is not common, overt hyperthyroidism can put both the mother and the fetus at risk. Due to the placental passage of thyroid hormones the fetus can present hyperthyroidism and $1-5 \%$ of the neonates can develop hyperthyroidism or Graves' disease. Fetal hyperthyroidism is associated with tachycardia ( $\geq 160$ beats/min), heart failure, hydrops, goiter and prematurity (8).

If untreated, it is associated with low birth weight, prematurity and eclampsia. Pregnant patients with hyperthyroidism have a higher risk of infertility and miscarriage than those with normal thyroid function (8). Previous findings correlated untreated Grave's disease with increased incidence of birth defects compared to euthyroid patients (32). Due to the 
Table I. Normal values for thyroid hormones.

\begin{tabular}{lcccc}
\hline & TSH $(8)$ & Free T3 (9) & Free T4 (9) & TBG (10) \\
\hline Non-pregnant (fertile period) & $0.5-4.1 \mathrm{mU} / \mathrm{l}(8)$ & $2.0-7.0 \mathrm{pmol} / \mathrm{l}(9)$ & $0.9-1.7 \mathrm{ng} / \mathrm{dl}(9)$ & $16-24 \mu \mathrm{g} / \mathrm{ml}(10)$ \\
First trimester & $0.6-3.4 \mathrm{mU} / \mathrm{l}(8)$ & $1.54-5.22 \mathrm{pmol} / 1(9)$ & $0.95-1.53 \mathrm{pmol} / \mathrm{l}(9)$ & $10-40 \mu \mathrm{g} / \mathrm{ml}(10)$ \\
Second trimester & $0.37-3.6 \mathrm{mU} / \mathrm{l}(8)$ & $1.78-5.29 \mathrm{pmol} / \mathrm{l}(9)$ & $0.87-1.45 \mathrm{pmol} / \mathrm{l}(9)$ & $23-46 \mu \mathrm{g} / \mathrm{ml}(10)$ \\
Third trimester & $0.38-4.0 \mathrm{mU} / \mathrm{l}(8)$ & & & $19-49 \mu \mathrm{g} / \mathrm{ml}(10)$ \\
\hline
\end{tabular}

influence of hCG on maternal thyroid, gestational hyperthyroidism must be considered and treatment before 18 weeks of pregnancy should not be initiated due to the possibility of normalized T4 levels in this period (31). After the exacerbation of symptoms in the first half of pregnancy when the TSH receptors are overstimulated by hCG, in the second half of the pregnancy the symptomatology improves and so the medical treatment must be adjusted accordingly (33). In these patients the aim is to keep fT4 levels at the upper normal range in order to use the minimum dose of anti-thyroid medication.

The risk for developing fetal hyperthyroidism is correlated with maternal hormone values, especially the stimulating antibodies in maternal-fetal circulation (34). Previous findings suggest that hyperthyroidism in neonates from mothers with Graves' disease can be up to 5\% (35). Fetal thyroid stimulation leads to fetal tachycardia, fetal goiter, prematurity, and hydrops (8).

In these cases, fetal surveillance includes screening ultrasound at 18-22 weeks for fetal thyroid anatomy, signs of growth restriction, hydrops, oligohydramnios or cardiac rhythm anomalies, and regular hormonal dosage, especially TRAb (29).

\section{Treatment options in pregnancy}

The medical treatment for hyperthyroidism is represented by anti-thyroid drugs. In pregnancy methimazole (MMI) and propylthiouracil (PTU) are commonly used. Carbimazole can be also used as it is metabolized to methimazole (36). The main concern is that anti-thyroids cross the placenta (17). Even if it is unclear whether there is a significant difference between PTU and MMI regarding crossing the placenta, there is a strong recommendation that the lowest possible dose be used. It is recommended that in the first trimester PTU is recommended while it appears that MMI can cross the placenta more freely (37). In addition, PTU is bound tightly to serum albumin, although there is evidence that the placental crossing is not entirely dependent on protein transfer (38).

Even though hyperthyroidism itself can be associated with increased risk of congenital anomalies (most frequently cardiac or renal) (8), anti-thyroid treatment can cause teratogenicity (37). Anomalies associated with this treatment are represented by congenital aplasia cutis reported in old studies (scalp defect due to MMI in the first trimester) (39), choanal atresia, tracheo-oesophageal fistula, gastrointestinal anomalies in particular oesophageal atresia and patent vitellointestinal duct, omphalocele, athelia/hypothelia, developmental delay, hearing loss, and dysmorphic facial features (37). All these anomalies form a specific phenotype that is seen in fetuses of mothers that received treatment with carbimazole. These types of rare defects are not seen in patients with PTU treatment and so the recommendation is that this drug be used in the first trimester (40). Both drugs are responsible for fetal hypothyroidism and goiter; nevertheless, the maternal thyroid hormone levels must be adjusted as they are more important than the drug being used $(37,41)$.

\section{Thyroid dysfunction treatment in lactation period}

WHO recommends breastfeeding up to 2 years and exclusive breastfeeding in the first 6 months. Both hyperthyroidism and hypothyroidism need adequate treatment in the post-partum period and probably long-term treatment.

In hyperthyroidism the main indication is PTU. The amount excreted in breast milk is $0.025 \%$. In the case of MMI the amount excreted in breast milk is equivalent to the maternal levels of the drugs (42). Studies that evaluated thyroid function of infants with MMI treatment have shown no difference from infants of euthyroid mothers (36).

Breastfeeding is considered to be safe for patients with PTU $\leq 300 \mathrm{mg} / \mathrm{day}$ or MMI $20-30 \mathrm{mg} /$ day and close monitoring of fetal thyroid function (36).

Normal thyroid hormones levels are needed for normal milk production and normal lactation. Breastfed infants of mothers with thyroid dysfunction should be evaluated for normal growth and development and normal thyroid function.

\section{Conclusion}

The European Thyroid Association reported that the clinical practice and recommendation are variable in Europe and there is inconsistency in the treatment on pregnant women or on those desiring pregnancy that present with hyperthyroidism. The current recommendations (the American Thyroid Association, the American Association of Clinical Endocrinologists, the Endocrine society) are that PTU should be used in the first trimester and be switched to MMI from the second trimester. If the patient is under MMI, they should transfer to PTU when pregnancy is confirmed. The Endocrine Society recommends that, after changing from PTU to MMI, the thyroid function should be tested at 2 weeks (43).

One particular case is represented by the thyroid storm that can also occur in a pregnant patient and that can put the mother and the baby at risk. The patient reported fever, tachycardia, hypertension and altered thinking. In this case, it is recommended that women be admitted to the intensive care 
unit. The treatment is represented by fluid support, antipyretics (Thylenol), and anti-thyroid medication (30 mg MMI or $300 \mathrm{mg}$ PTU every $6 \mathrm{~h}$ ). After the first hour, iodine supplementation is necessary and also hydrocortisone to block the conversion of T4 to T3 and beta blockers to control tachycardia (36).

With proper management, constant follow-up and well-adjusted anti-thyroid treatment the mother-fetal outcome should not be affected.

\section{Acknowledgements}

Not applicable.

\section{Funding}

No funding was received.

\section{Availability of data and materials}

The data used in the current paper are available from the mentioned databases. The synthetized data from the articles are available in the annexed table.

\section{Authors' contributions}

All the authors contributed to the article. MCD drafted the manuscript and critically revised the final form, AEN substantially contributed to the conception of the work and synthetized the information, SF researched and interpreted the literature, CGN conceived the work and critically revised the manuscript, AP and AVC researched the literature and drafted the manuscript, RCP researched the literature and AVC approved the final form. All authors read and approved the final manuscript.

\section{Ethics approval and consent to participate}

Not applicable.

\section{Patient consent for publication}

Not applicable.

\section{Competing interests}

The authors declare that they have no competing interests.

\section{References}

1. Monaco F: Classification of thyroid diseases: Suggestions for a revision. J Clin Endocrinol Metabolism 88: 1428-1432, 2021.

2. Andersen SL and Knøsgaard L: Management of thyrotoxicosis during pregnancy. Best Pract Res Clin Endocrinol Metab 34: 101414, 2020.

3. Dumitrascu MC, Iliescu M, Petca RC, Sandru F, Mehedintu C, Farcasanu PD, Maru N, Chibelean C and Petca A: The chemical pregnancy. Revista de Chimie 70: 3814-3823, 2019.

4. Alemu A, Terefe B, Abebe M and Biadgo B: Thyroid hormone dysfunction during pregnancy: A review. Int J Reprod Biomed 14: 677-686, 2016.

5. Spencer L, Bubner T, Bain E and Middleton P: Screening and subsequent management for thyroid dysfunction pre-pregnancy and during pregnancy for improving maternal and infant health Cochrane Database Syst Rev 9: CD011263, 2015.
6. Šimják P, Anderlová K, Cinkajzlová A, Pařízek A, Kršek M and Haluzík M: The possible role of endocrine dysfunction of adipose tissue in gestational diabetes mellitus. Minerva Endocrinol 45: 228-242, 2020

7. Dumitrascu MC, Stanescu AMA, Bejan C, Sandru F, Toader DO, Radavoi DG, Cotirlet A, Pusta CTJ and Diaconu CC: Obesity and its implications on Stress Urinary Incontinence. Revista de Chimie 70: 3660-3662, 2019.

8. Azizi F and Amouzegar A: Management of hyperthyroidism during pregnancy and lactation. Eur J Endocrinol 164: 871-876, 2011.

9. Cignini P, Cafà EV, Giorlandino C, Capriglione S, Spata A and Dugo N: Thyroid physiology and common diseases in pregnancy: Review of literature. J Prenat Med 6: 64-71, 2012.

10. Casey B and Leveno K: Thyroid disease in pregnancy. Obstet Gynecol 108: 1283-1292, 2006.

11. Skjöldebrand L, Brundin J, Carlström A and Pettersson T: Thyroid associated components in serum during normal pregnancy. Acta Endocrinol (Copenh) 100: 504-511, 1982.

12. Vadiveloo T, Donnan PT, Murphy MJ and Leese GP: Age- and gender-specific TSH reference intervals in people with no obvious thyroid disease in Tayside, Scotland: The thyroid epidemiology, audit, and research study (TEARS). J Clin Endocrinol Metab 98: 1147-1153, 2013.

13. Karakosta P, Chatzi L, Bagkeris E, Daraki V, Alegakis D, Castanas E, Kogevinas M and Kampa M: First- and second-trimester reference intervals for thyroid hormones during pregnancy in 'Rhea' mother-child cohort, Crete, Greece. J Thyroid Res 2011: 490783, 2011.

14. Kratz A, Ferraro M, Sluss PM and Lewandrowski KB: Case records of the Massachusetts General Hospital. Weekly clinicopathological exercises. Laboratory reference values. N Engl J Med 351: 1548-15632, 2004.

15. Alexander EK, Pearce EN, Brent GA, Brown RS, Chen H, Dosiou C, Grobman WA, Laurberg P, Lazarus JH, Mandel SJ, et al: 2017 Guidelines of the American Thyroid Association for the Diagnosis and Management of Thyroid Disease During Pregnancy and the Postpartum. Thyroid 27: 315-389, 2017.

16. Thyroid disease in pregnancy: ACOG practice bulletin, number 223. Obstet Gynecol 135: e261-e274, 2020.

17. Krassas GE, Poppe K and Glinoer D: Thyroid function and human reproductive health. Endocr Rev 31: 702-755, 2010.

18. Woodworth A and Schuler EE: Thyroid testing algorithms in pregnancy. Clinical Laboratory News. https://www.aacc. org/cln/articles/2018/august/thyroid-testing-algorithms-in-pregnancy. Accessed August 1, 2018.

19. Lazarus JH: Thyroid disorders associated with pregnancy: Etiology, diagnosis, and management. Treat Endocrinol 4: 31-41, 2005.

20. Glinoer D, Spencer CA: Serum TSH determinations in pregnancy: How, when and why? Nat Rev Endocrinol 6: 526-529, 2010.

21. Tan JY, Loh KC, Yeo GS and Chee YC: Transient hyperthyroidism of hyperemesis gravidarum. BJOG 109: 683-688, 2002.

22. Gerhard I and Runnebaum B: Predictive value of hormone determinations in the first half of pregnancy. Eur J Obstet Gynecol Reprod Biol 17: 1-17. 1984.

23. Nwabuobi C, Arlier S, Schatz F, Guzeloglu-Kayisli O, Lockwood CJ and Kayisli UA: hCG: Biological functions and clinical applications. Int J Mol Sci 18: 2037. 2017.

24. Negro R and Stagnaro-Green A: Clinical aspects of hyperthyroidism, hypothyroidism, and thyroid screening in pregnancy. Endocr Pract 20: 597-607, 2014.

25. Cooper DS and Laurberg P: Hyperthyroidism in pregnancy. Lancet Diabetes Endocrinol 1: 238-249, 2013.

26. Sarkar S and Bischoff LA: Management of hyperthyroidism during the preconception phase, pregnancy, and the postpartum period. Semin Reprod Med 34: 317-322, 2016.

27. Stagnaro-Green A, Dong A and Stephenson MD: Universal screening for thyroid disease during pregnancy should be performed. Best Pract Res Clin Endocrinol Metab 34: 101320, 2020.

28. Illouz F, Luton D, Polak M, Besançon A and Bournaud C: Graves' disease and pregnancy. Ann Endocrinol (Paris) 79: 636-646, 2018.

29. Sorah K and Alderson TL: Hyperthyroidism in pregnancy. In: StatPearls [Internet]. Treasure Island (FL),StatPearls Publishing, 2020. https://www.ncbi.nlm.nih.gov/books/NBK559203/. Accessed Februart 3, 2021. 
30. Delitala AP, Capobianco G, Cherchi PL, Dessole S and Delitala G: Thyroid function and thyroid disorders during pregnancy: A review and care pathway. Arch Gynecol Obstet 299, 327-338, 2019.

31. Moleti M, Di Mauro M, Sturniolo G, Russo M and Vermiglio F Hyperthyroidism in the pregnant woman: Maternal and fetal aspects. J Clin Transl Endocrinol 16: 100190, 2019.

32. Mitsuda N, Tamaki H, Amino N, Hosono T, Miyai $\mathrm{K}$ and Tanizawa O: Risk factors for developmental disorders in infants born to women with Graves disease. Obstet Gynecol 80: 359-364, 1992.

33. Patil-Sisodia K, Mestman JH: Graves hyperthyroidism and pregnancy: A clinical update. Endocr Pract 16: 118-129, 2010.

34. Laurberg P, Nygaard B, Glinoer D, Grussendorf M and Orgiazzi J: Guidelines for TSH-receptor antibody measurements in pregnancy: Results of an evidence-based symposium organized by the European Thyroid Association. Eur J Endocrinol 139: 584-586, 1998

35. Weetman AP: Graves' disease. N Engl J Med 343: 1236-1248, 2000.

36. Moore LE: Thyroid disease in pregnancy: A review of diagnosis, complications and management. World J Obstet Gynecol 5: 66-72, 2016.
37. Taylor PN and Vaidya B: Side effects of anti-thyroid drugs and their impact on the choice of treatment for thyrotoxicosis in pregnancy. Eur Thyroid J 1: 176-185, 2012.

38. Momotani N, Noh JY, Ishikawa N and Ito K: Effects of propylthiouracil and methimazole on fetal thyroid status in mothers with Graves' hyperthyroidism. J Clin Endocrinol Metab 82: 3633-3636, 1997.

39. Milham S and Elledge W: Maternal methimazole and congenital defects in children. Teratology 5: 125-126, 1972.

40. Bowman P, Osborne NJ, Sturley R and Vaidya B: Carbimazole embryopathy: Implications for the choice of antithyroid drugs in pregnancy. QJM 105: 189-193, 2012

41. Cooper DS: Antithyroid drugs. N Engl J Med 352: 905-917, 2005.

42. Karras S and Krassas GE: Breastfeeding and antithyroid drugs: A view from within. Eur Thyroid J 1: 30-33, 2012.

43. De Groot L, Abalovich M, Alexander EK, Amino N, Barbour L, Cobin RH, Eastman CJ, Lazarus JH, Luton D, Mandel SJ, et al: Management of thyroid dysfunction during pregnancy and postpartum: An Endocrine Society clinical practice guideline. J Clin Endocrinol Metab 97: 2543-2565, 2012. 